\title{
PENATAAN TATA INFORMASI SEBAGAI PENANDA VISUAL KAWASAN DI KORIDOR JAMIN GINTING PANCUR BATU
}

\author{
Nasruddin ${ }^{1}$, Beny O.Y Marpaung ${ }^{2}$ \\ ${ }^{1,2}$ Program Studi Magister Teknik Arsitektur Fakultas Teknik Universitas Sumatera Utara \\ Jl. Perpustakaan St. J07 Building, Medan, 20155, Indonesia \\ *Email: ${ }^{2}$ nass_arch@yahoo.co.id, ${ }^{2}$ beny.marpaung@usu.ac.id
}

\begin{abstract}
The existence of signage system is an identity and marker of area. The signage system in Jamin Ginting Street, Pancur Batu was chaotic and irregular. Jamin Ginting Street, Pancur Batu was located in Deli Serdang District, North Sumatera Province. This area was known as trade and service area. The lack of signage system arrangement guidance creates Jamin Ginting Street, Pancur Batu area was looked irregularly, slums, and distracting visually. The purpose of research is to produce signage system arrangement guideline so that create area more well organized, informative, and as marker area. This research took study about information arrangement, signage placement, street guide, advertisementand information media. The research was used qualitative descriptive analysis method. The expectation of this paper is to produce signage system arrangement guideline so therefore can improvethe identity of area and generating a visual arrangement. In conclusion, with well arrangement of signage system will improve visual aesthetic of building and area. With the appropriate of arrangement, information will be delivered more effective.
\end{abstract}

Keywords: signage system, visual markers, area identity.

\section{PENDAHULUAN}

Koridor jalan Jamin Ginting kecamatan Pancur Batu berada di Kabupaten Deli Serdang Provinsi Sumatera Utara, jalan ini merupakan akses dari Kota Medan menuju Sibolangit dan Berastagi. Kawasan ini dikenal sebagai dengan fungsi permukiman, perdagangan dan jasa. Sepanjang koridor Jalan Jamin Ginting kecamatan Pancur Batu ini banyak ditemukan tata informasi. Jenis tata informasi yang terdapat diantaranya papan nama kantor, papan petunjuk informasi, papan penunjuk arah, dan ramburambu lalu lintas. Tidak adanya penataan pada pemasangan tata informasi mengakibatkan kawasan koridor Jalan Jamin Ginting terkesan kurang teratur. Tidak tertata dengan tepat tata informasi secara desain maupun peletakan menyebabkan pencemaran visual.

Tata informasi atau dengan kata lain Sign System, menurut Shirvani Hamid (1985) termasuk dalam delapan aspek elemen perkotaan, signage merupakan bentuk-bentuk informasi dan orientasi kota yang di rancang khusus menjadi bagian dari elemen kota. Penataan tata informasi diperlukan untuk mencapai keseragaman bentuk, dalam menciptakan tampilan koridor yang menarik serta memudahkan penyampaian informasi bagi para pejalan kaki dan pengemudi kendaraan bermotor.

Adapun tujuan dari penataan tata informasi atau signage system adalah:

1. Menghindari kekacauan dan kesemrautan wajah kota.

2. Memberikan informasi yang jelas.

3. Menciptakan daya tarik.

4. Menuntun pada penciptaan cita rasa kota yang tertata.

\section{LANDASAN TEORI}

\section{Studi Literatur}

Sistem tata informasi atau dalam urban desain di sebut signage sytem merupakan hal penting sebagai penanda suatu tempat atau kawasan. Menurut Whitbread dalam The Design Manual (2009),Signage adalah suatu penanda dari variasi teks dan simbol yang di pasang pada daerah yang mempunyai pergerakan yang tinggi, tanpa bergantung 
bahasa verbal tertentu. Berhubungan dengan aspek lingkungan Rubenstein (1996) mendefinisikan bahwa signage merupakan sistem tanda bagian dari bidang komunikasi visual yang berfungsi sebagai sarana informasi dan komunikasi secara arsitektural. Dengan demikian, dapat disimpulkan bahwa signage adalah media komunikasi visual yang menginformasikan pesan melalui integrasi bahasa visual dengan objek dan lingkungannya.

Prinsip-prinsip desain signage system di ataranya adalah:

1. Visibility, dapat terlihat dari aspek lokasi atau penempatan, standar ketinggian dan lebar penggunaan material dari yang mengganggu.

2. Legibility, dapat terbaca oleh pengendara. Dari komposisi dan type, huruf, jarak dan penempatan antar satu dengan lainnya.

3. Harmony dengan arsitektur bangunan serta lingkungan.

Kriteria tata informasi atau Sign sytem Menurut Julianto (2010) Signage system harus memenuhi empat kriteria yaitu: Mudah dilihat, mudah dibaca, mudah dimengerti dan mudah dipercaya. Adapun jenis-jenis Sign System diataranya adalah:

1. Tanda pengenal (Identification) adalah tanda yang di gunakan untuk membedakan antara suatu objek dengan objek lainnya, seperti identitas kantor, gedung perusahaan atau produk.

2. Tanda penunjuk informasi, adalah tanda yang berfungsi untuk mengarahkan suatu objek atau sasaran dengan menginformasikan dimana suatu lokasi atau benda tertentu berada.

3. Tanda penunjuk arah (direction) adalah tanda yang mencakup arah panah yang mampu mengarahkan objek sasaran menuju suatu tempat, seperti ruangan jalan dan fasilitas lain.

4. Tanda larangan dan peringatan (regulation), adalah tanda yang bertujuan untuk menginformasikan mengenai apa yang tidak boleh di kerjakan atau di larang, selain itu penanda ini juga menginformasikan audiens untuk berhati-hati.

5. Tanda pemberitahuan resmi, tanda ini menunjukkan informasi tentang pemberitahuan resmi agar tidak di kacaukan dengan tanda-tanda penunjuk.
Sign system dalam konteks desain komunikasi visual, menurut Sumbo Tinarbuko (2012) merupakan rangkaian representasi visual yang memiliki tujuan sebagai media interaksi manusia dalam ruang public (Gambar 1 dan 2). Sign system di bagi menjadi empat kelompok yaitu:

1. Traffic Sign, adalah tata informasi bertujuan untuk memberikan petunjuk jalan, petunjuk arah, larangan dan peringatan.

2. Commercial Sign, adalah tata informasi yang bertujuan untuk perdagangan, bertujuan untuk memasarkan suatu produk.

3. Wayfinding Sign, adalah tata informasi yang bertujuan memberikan petunjuk jalan dan penunjuk arah.

4. Safety Sign, adalah tata informasi yang bertujuan memberikan pesan peringatan, himbauan, kepada pemakai tentang suatu sistem keamanan.

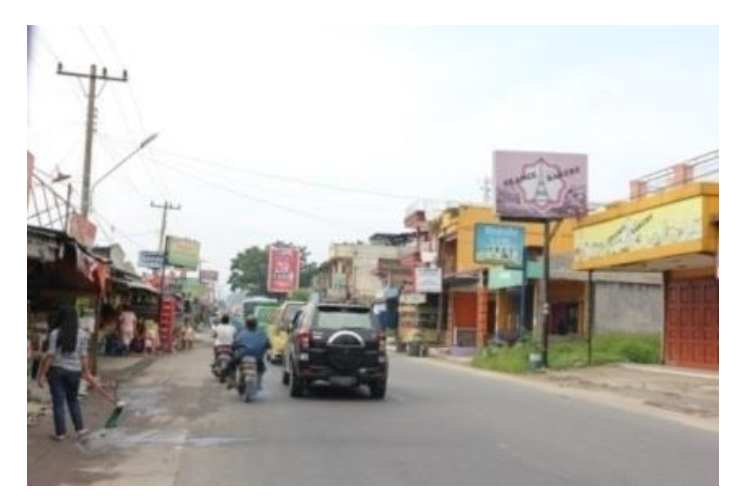

Gambar 1. Ilustrasi tata informasi yang terdapat di Jalan Jamin Ginting kecamatan Pancur Batu

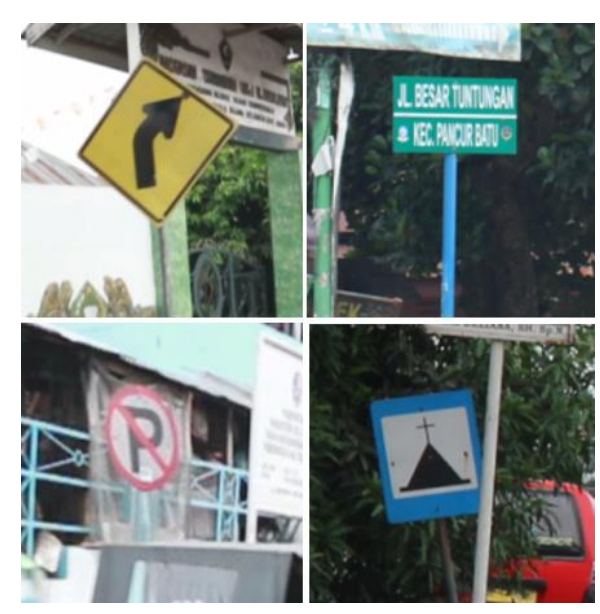

Gambar 2. Jenis rambu-rambu yang terdapat di koridor jalan Jamin Ginting Pancur Batu 
Keberadaan rambu lalu lintas yang berada di koridor Jalan Jamin Ginting Pancur batu merupakan bagian dari tata informasi. Menurut Peraturan Menteri Perhubungan Republik Indonesia Nomor Pm 13 Tahun 2014 Tentang Rambu Lalu Lintas, berdasarkan jenisnya rambu lalu lintas terdiri dari:

1. Rambu peringatan.

2. Rambu larangan.

3. Rambu perintah.

4. Rambu petunjuk.

Adanya peraturan tentang penempatan rambu-rambu lalu lintas maka akan menciptakan koridor jalan aman dan memudahkan bagi pengendara kendaraan bermotor melintasi kawasan tersebut.

Nilai visual dapat dikatakan berkaitan dengan skala, pola, warna, tekstur dan dimensi. Dalam hal ini aspek visual penataan tata informasi berkaitan dengan jumlah papan informasi, lokasi penempatan, ukuran, warna dan pencahayaan. Bahasa visual berhubungan dengan garis warna dan komposisi. Menurut Shirvani (1985) Ukuran dan kualitas rancangan sign system harus diatur supaya harmonis, dapat mengurangi kesemrautan dan persaingan antara papan informasi yang bersifat komersial dan nonkomersial serta papan informasi lalulintas. Baerdasarkan hal tersebut keberadaan papan informasi diharapkan menjadi teraratur dan tidak menjadi tumpang tindih.

\section{Studi Banding Penataan Tata Informasi}

Tata informasi secara umum di sesuaikan dengan kebijakan pemerintah daerah. Pada pelaksanaan teknis di lapangan setiap daerah memiliki ketentuan khusus masing-masing. Studi banding dilakukan untuk mendapatkan masukan tentang penataan tata informasi sehingga dapat menjadi pembanding serta contoh penerapan nya.

Studi banding signage sytem berkenaan dengan tata informasi lalu lintas di Kota Jogjakarta di desain dengan berbasis pada nilainilai luhur lokal. Penerapan nilai lokal pada tata informasi adalah dengan menempatkan aksara jawa pada rambu-rambu penunjuk jalan dan nama kota di taman kota, hal tersebut dimaksudkan untuk memperkuat identitas kawasan dan menjaga nilai-nilai lokal agar tetap terjaga. Penempatan di lakukan pada penunjuk jalan, nama lingkungan dan tempat-tempat wisata. Selain itu desainnya menerapkan bentuk dan memasukkan unsur etnik pada bagianbagian papan nama (Gambar 3).

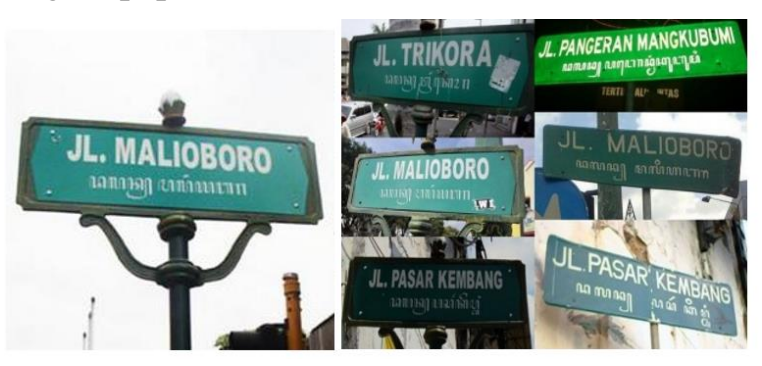

Gambar 3. Papan nama jalan di Kota Jogjakarta Sumber: http://sekti.blog.ugm.ac.id/

Studi banding signage sytem berkenaan dengan penataan lalu lintas di Southlake City (Gambar 4), pada kawasan ini perencanaan tata informasi membuat tiga konsep yaitu:

1. Unity with Variety. Serasi pada penggunaan bahan, warna, tanda font, dan unsur terkait pada koridor jalan.

2. Pulse Points. Penataan tata informasi pada persimpangan jalan.

3. Quality and Timelessness. Bentuk tata informasi yang memiliki unsur karakteristik nilai-nilai lokal serta bentuk desain yang tahan lama.

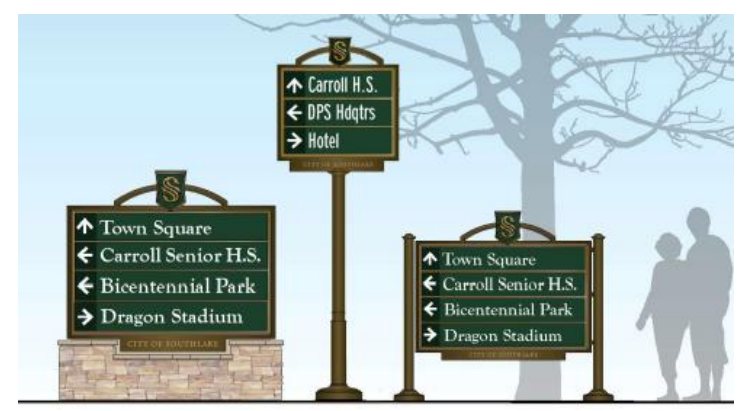

Gambar 4. Desain rambu nama jalan di Southlake Sumber: City of Southlake Wayfinding Sign System Plan, 2010

Penataan tata informasi dan rambu lalu lintas yang di lakukan di Southlake City, di kerjakan dengan seragam dan memiliki unsur satu kesatuan melalui bentuk desain, model dan penggunaan warna.

Studi banding signage sytem di City of St. Catharines (Gambar 5). Pada bangunan komersial, tata informasi didesain dengan skala manusia. Signage pada bagian muka bangunan terletak bagian dinding di atas etalase yang. Sistem tata informasi yang terletak pada dinding 
bangunan, signage tersebut menempati tidak lebih dari $15 \%$ luas permukaan dinding. Penempatan sistem tata informasi dimaksudkan untuk mempermudah pejalan kaki mengenal fungsi bangunan tersebut. Sistem tata informasi yang terletak pada bagian dinding bangunan tidak boleh menghalang bukaan bangunan. Signage seperti papan menu atau papan yang terletak pada jalur pejalan kaki tidak boleh melebihi ukuran $1.2 \mathrm{~m} 2$ dan tidak mengurangi jalur minimum pejalan kaki sebesar $2 \mathrm{~m}$. Sistem tata informasi seperti poster dan umbul-umbul dianggap sebagai penghalang visual antara jalan utama dengan bangunan komersial. Penggunaan signage gantung juga ditempatkan pada bagian sisi kanan bangunan baik dilantai pertama maupun lantai kedua.

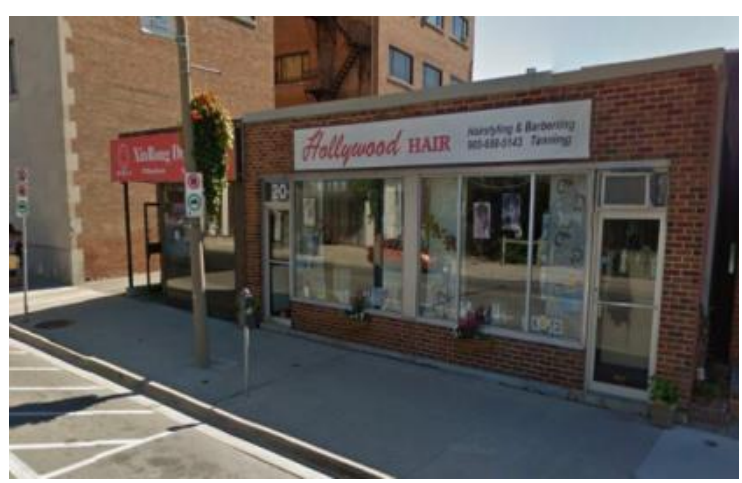

Gambar 5. Penataan nama toko di kota St. Catharines

Sumber: Down Town Urban Design Guidelines City of St. Catharines

\section{METODE PENELITIAN}

Penelitian dilakukan dengan metode analisis deskriptif kualitatif. Peneliti melakukan analisis terhadap keberadaan tata informasi pada lokasi penelitian kemudian melakukan studi literatur peraturan daerah terhadap penataan tata informasi, studi banding di lakukan untuk mendapatkan gambaran tentang penataan tata informasi. Lokasi penelitian berada pada koridor jalan Jamin Ginting Kecamatan Pancur Batu, Kabupaten Deli Serdang Provinsi Sumatera Utara. Panjang koridor lokasi penelitian lebih kurang 3 kilometer (Gambar 6).

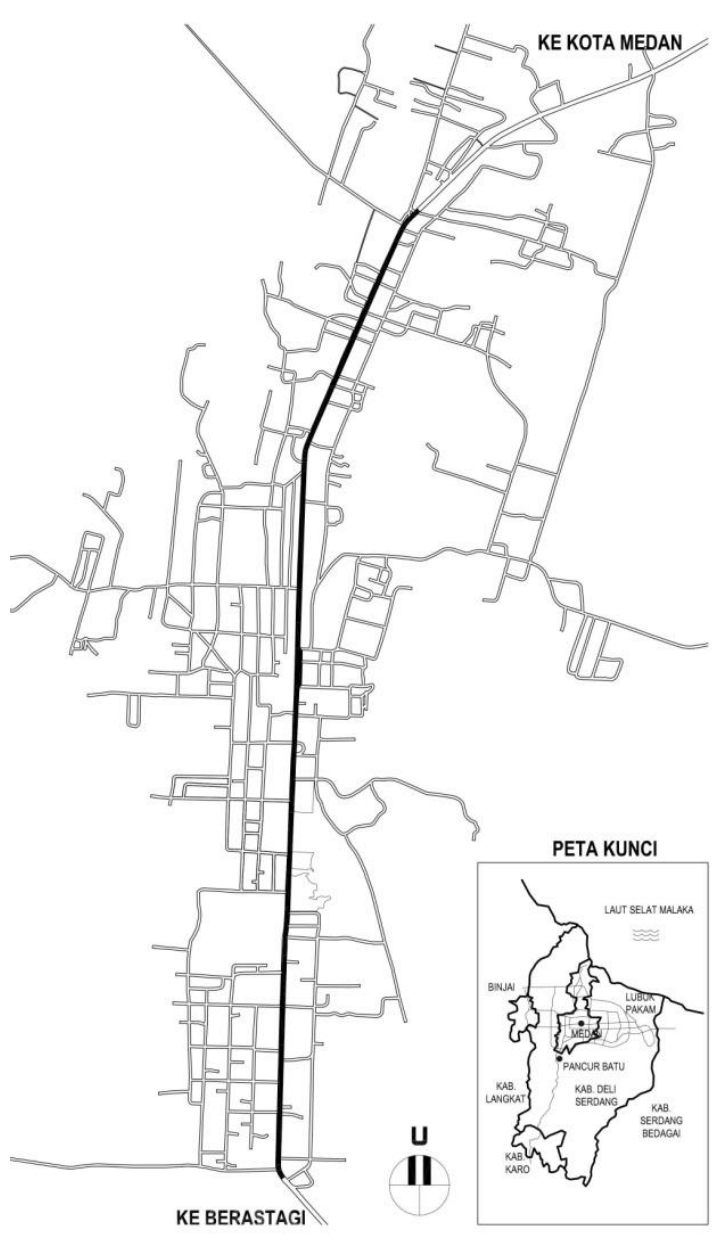

Gambar 6. Peta ilustrasi koridor jalan Jamin Ginting Kecamatan Pancur Batu, Kabupaten Deli Serdang Sumatera Utara

\section{HASIL DAN PEMBAHASAN}

\section{Tata Informasi di Koridor Jalan Jamin Ginting Pancur Batu}

Pancur Batu merupakan daerah lintasan dari Kota Medan ke Sibolangit dan Berastagi serta sebaliknya. Keberadaan tata informasi sebagai bagian dari fungsi kawasan perdagangan dan jasa. Jenis papan informasi yang di jumpai diataranya adalah papan nama toko, neon box, baliho, papan nama kantor, spanduk dan rambu lalulintas.

Area pasar Pancur Batu terdapat deretan pertokoan yang memiliki unsur sejarah yang merupakan pertokoan model lama yang dipengaruhi gaya arsitektur Melayu dan Cina, penempatan reklame yang menutupi bagian fasade bangunan pertokoan akan mengurangi nilai kesejarahan di deretan pertokoan tersebut. Terdapat bagian muka toko/fasade di lantai II 
yang dipasang media iklan atau reklame secara penuh. Selain itu pemilik pertokoan memasang spanduk yang berfungsi ganda sebagai nama toko juga untuk penghalang silau cahaya matahari. Terdapat reklame dari sponsor yang di pasang menggantung pada bagian depan petokoan (Gambar 7).

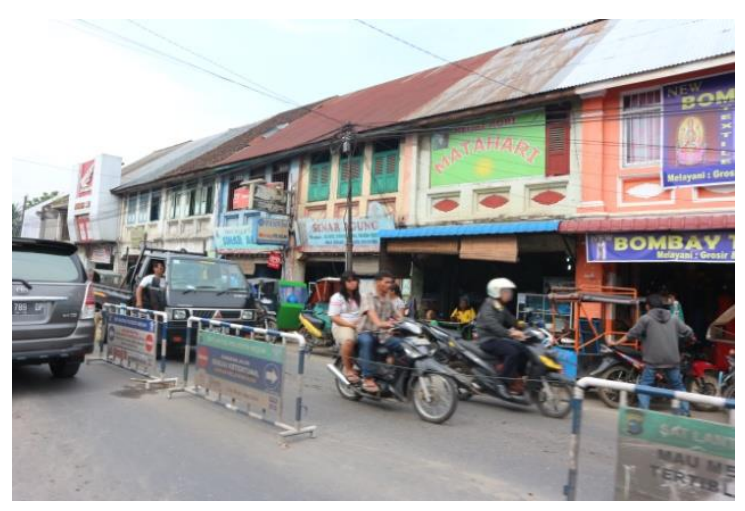

Gambar 7. Pertokoan di pasar Pancur batu

Tata informasi berupa reklame yang memperkenalkan suatu produk merupakan salah satu sumber pendapatan daerah yang di peroleh melalui pajak dan retribusi pemasangan iklan atau reklame. Banyak nya reklame dengan cara menempatkan iklan sekaligus sebagai nama toko oleh pihak sponsor dapat dianggap sebagai cara untuk menghindari retribusi. Hal ini apabila berlangsung terus menerus akan merugikan pendapatan daerah.

Dalam Peraturan Daerah Kabupaten Deli Serdang Nomor 6 Tahun 2011 Tentang Perizinan Tertentu, Pasal 140 menyatakan Setiap pribadi atau badan yang menyelenggarakan reklame harus memiliki izin dari Bupati, Pemasangan reklame tidak boleh menggangu keamanan, ketertiban, keindahan dan tidak menggangu pemandangan pengemudi lalu lintas (Gambar 8 dan 9).

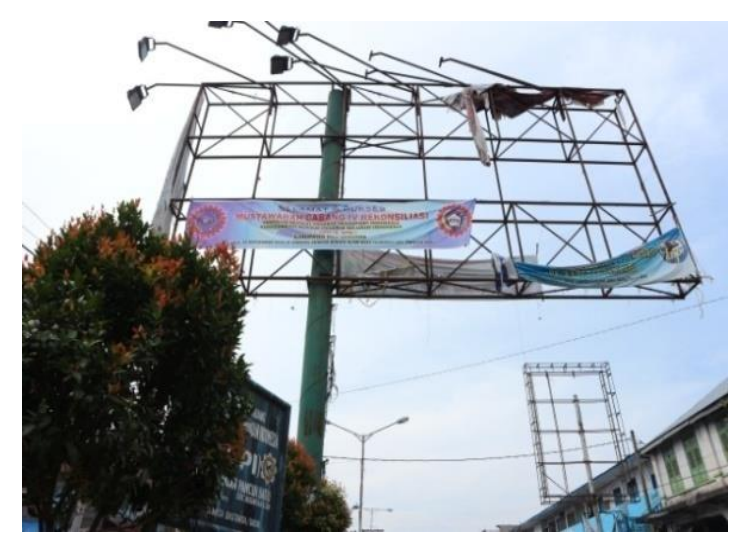

Gambar 8. Spanduk yang dipasang pada baliho resmi

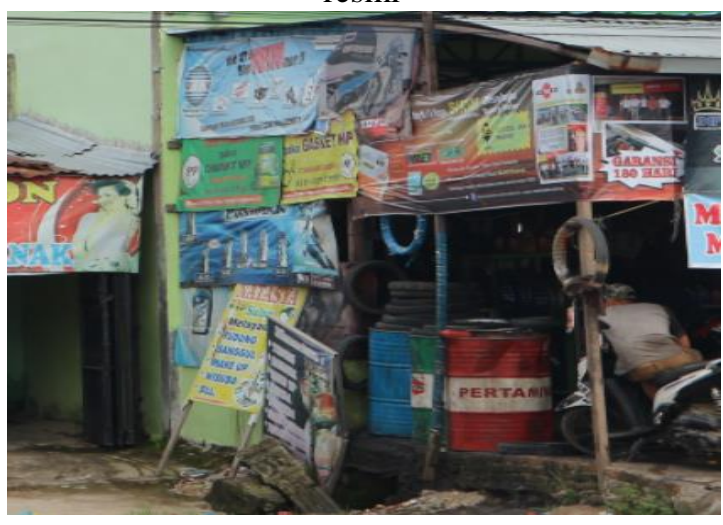

Gambar 9. Pemasangan spanduk sponsor yang tak beraturan akan menggangu secara visual

Belum adanya peraturan khusus menyangkut tentang penataan papan reklame di Kabupaten Deli Serdang, apabila merujuk contoh dari Kota Medan yang di atur dalam Peraturan Walikota Medan nomor 38 Tahun 2014 tentang penataan reklame, pada Bab III Penataan bangunan reklame. Penempatan lokasi, pengaturan ketinggian, dan jarak bangunan reklame. Konstruksi reklame harus memenuhi persyaratan teknis, tidak menggangu fungsi atau merusak sarana dan prasarana kota serta tidak menutup pandangan terhadap rambu lalu lintas.

Papan informasi yang di pasang di koridor jalan Jamin Ginting Pancur Batu memberikan kesan saling mendominasi sehingga terlihat menggangu visual. Keberadaan tata informasi tersebut sebagai alat penanda bagi setiap toko/tempat usaha perdagangan dan jasa. Agar tidak berkesan semmraut maka diperlukan nya pengaturan dan penempatan yang berguna untuk kesan visual kawasan. Berdasarkan studi literatur maka beberapa hal yang perlu di tata untuk mendapatkan keseragaman visual yaitu berkaitan dengan penempatan, ukuran, ketinggian, dan luasan. Beberapa studi aturan untuk penataan tata informasi adalah seperti berikut ini (Gambar 10, 11, dan 12).

1. Papan nama toko/tempat usaha yang menempel pada dinding depan adalah tidak lebih dari 15\% dari luas dinding. Peletakan papan nama adalah di lantai I pada dinding bagian atas. Setiap peletakan harus di tata agar serasi dengan toko atau tempat usaha di sebelahnya. 
2. Papan reklame yang berada di dinding depan bangunan hanya boleh diletakkan pada lantai dua dengan luas maksimal $50 \%$ dari luas dinding bagian depan lantai dua.

3. Papan iklan layanan masyarakat yang di selenggarakan oleh sponsor, wajib memiliki izin dari pemerintah daerah setempat, luas bidang sponsor adalah $10 \%$ dari luas keseluruhan panil papan iklan.

4. Papan nama neon box toko/tempat usaha yang terletak di depan persil memiliki ukuran luas maksimal 1,2 $\mathrm{m} 2$ dengan ketinggian 2 meter dari atas tanah. Jarak minimal antara satu dan lainnya adalah 2 meter.

5. Papan reklame/baliho berukuran $3 \times 6$ meter, dengan ketinggian papan panel dari tanah adalah 3 meter. Bagian sisi papan panel tidak boleh menjorok ke arah badan jalan. Jarak antara satu dan lainnya adalah 25-50 meter.

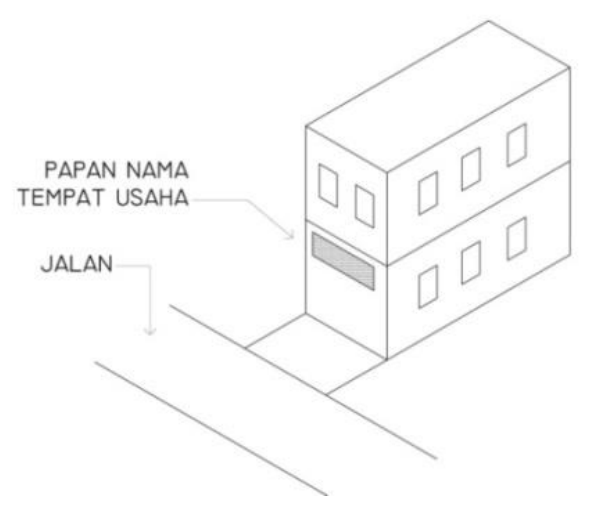

Gambar 10. Penempatan letak papan nama toko/tempat usaha pada bgaian muka bangunan

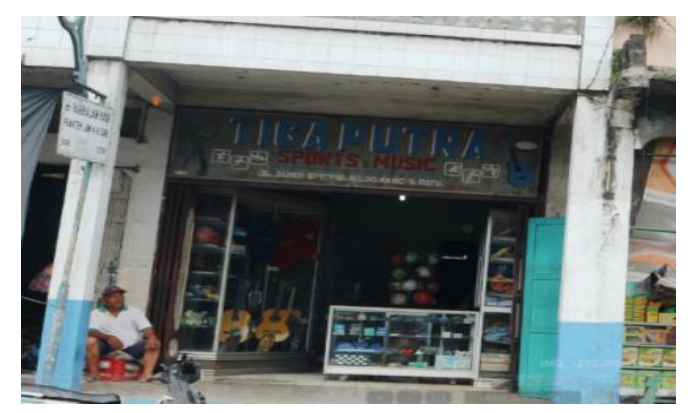

Gambar 11. Nama papan toko/tempat usaha yang di letakkan pada dinding lantai I bagian atas
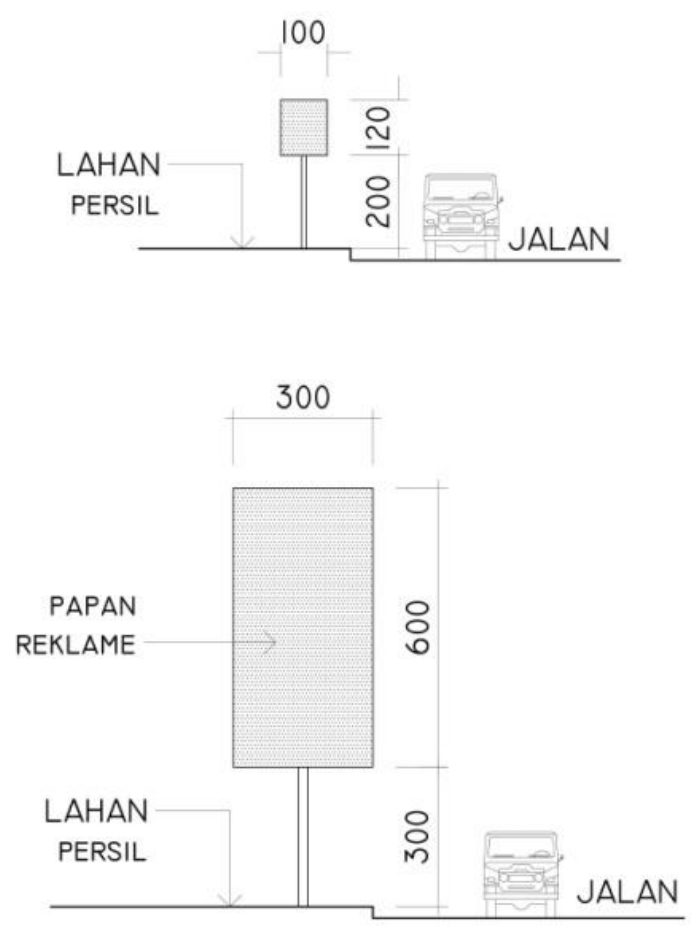

Gambar 12. Ukuran papan neon box nama tempat usaha dan dan ukuran baliho

Dengan adanya ketentuan dan peraturan pada peletakan tata informasi diharapkan dapat menciptakan keberadaan tata informasi yang teratur dan seragam.

\section{KESIMPULAN}

Keberadaan tata informasi atau Signage System merupakan bagian dari elemen perkotaan. Dengan penataan yang tepat akan menghasilkan rupa ruang kota yang teratur dan tertata sehingga menarik secara visual. Keberadaan tata informasi merupakan bagian penting dalam menjelaskan identitas dan sebagai penanda suatu kawasan.

Reklame atau iklan merupakan bagian dari tata informasi, perlunya sosialisasi untuk izin pemasangan reklame sehingga penempatan reklame akan terkontrol dan akan mendapatkan pemasukan daerah dari pajak dan retribusi.

Pemerintah daerah setempat perlu mengeluarkan kebijakan berkaitan dengan penataan sistem tata informasi dan pemasangan berbagai bentuk media reklame sehingga memiliki aturan yang jelas secara teknis maupun secara administrasi. Disamping itu perlunya 
memasukkan ilai-nilai lokal pada penataan tata informasi untuk melestarikan budaya lokal dan memeperkuat identitas kawasan.

\section{Daftar Pustaka}

Aniendya Christianna (2012) Design Signage sebagai Solusi pencemaran Visual, Universitas Kristen Petra Surabaya, Hal. 1-11.

Bertha Bintari (2011) Informasi Visual Dalam Arsitektur Rupa Ruang Kota, Jurnal Arsitektur Universitas Bandar Lampung edisi Juni 2011, Hal. 59-69.

City of Southlake Wayfinding Sign System Plan (2010).

Down Town Urban Design Guidelines City of St. Catharines (2012).

Peraturan Daerah Kabupaten Deli Serdang Nomor 6 Tahun 2011 tentang Perizinan Tertentu

Peraturan Menteri Perhubungan Republik Indonesia Nomor Pm 13 Tahun 2014 Tentang Rambu Lalu Lintas

Peraturan Walikota Medan Nomor 38 Tahun 2014 Tentang Penataan Reklame

Pelang Jalan Malioboro, 2012, (http://sekti.blog.ugm.ac.id/2012/11/23/j alan-malioboro/) di akses 7 januari 2017

Shirvani Hamid (1985) The Urban Design Process, New York, Van Nostrand Reinhold Company Inc

Sumbo Tinarbuko (2012) Semiotika Komunikasi Visual, Yogyakarta Jalasutra. 